\title{
Towards a developmental understanding of violence
}

\author{
PETER FONAGY
}

Young offenders (under 20 years old) account for more than half of the violent crimes in the UK. Statistics on the onset of serious and violent delinquency show us that about half of persistent juvenile offenders are 'active' by age 12-13 years. Prevalence peaks between the ages of 17 and 18 , but most serious delinquent offenders have started their offending careers much earlier.

Adolescents, as Poirot might have said, possess both the means (physical strength, cognitive competence), the opportunity (greater freedom from supervision and more access to resources) and the motive (pressure to perform at school, in a career, in sexual relationships). This undoubtedly explains why individuals are most likely to resort to violent behaviour in adolescence. A detailed longitudinal study of a birth cohort of 1037 young people followed from age 3 years to 26 years (Moffitt et al, 2002) showed that most adolescents will commit some delinquent act, but usually this will be a minor infraction. Only a small proportion of adolescents (around 6\%) are the persistent offenders who account for the majority of violent acts. Tracing the development of these young people's aggression has been a major challenge.

\section{VIOLENCE IS UNLEARNED, NOT LEARNED}

Recent epidemiological data have clarified that if children are followed from school entry to the end of adolescence, the frequency with which they are likely to resort to physical aggression, as reported by parents, teachers, peers or themselves, decreases with age. Physical aggression peaks at perhaps around the second year of life, and subsequently shows distinct developmental trajectories in different individuals (Nagin \& Tremblay, 2001; Shaw et al, 2003). These new data have shifted the emphasis of the developmental understanding of violence. Historically, models of aggression have tended to focus on how human aggression is acquired. Yet aggression appears to be there as a problem from early childhood, arguably from toddlerhood and perhaps from birth. Violence ultimately signals the failure of normal developmental processes to deal with something that occurs naturally.

Freud suggested (and is supported by modern developmental data) that social experience is there to tame a destructiveness inherent in humanity. Biological predisposition and social influence do not create destructiveness, but rather compromise the social processes that normally regulate and tame it. Not that aggression always shows the failure of some system: the innate aggression theory must take proper account of the existence of positive, survival-oriented aggression and also of aggression that is a genuine protest against hardship in life.

\section{AT TACHMENT ENABLES THE MASTERY OF AGGRESSION}

Understanding the development of violence as a failure of the normal developmental process allows us to reconsider what we know about risk. Among the important evolutionary purposes of attachment is the socialisation of natural aggression. Selfcontrol is developed through the efficient exercise of attentional mechanisms and symbolisation. A recent study of 310 boys from low-income homes followed between the ages of 18 months and 6 years examined the child's capacity to regulate anger in a frustration task (Gilliom et al, 2002). Boys classified as secure at the age of 18 months were more likely to disengage from frustrating stimuli and to ask when and how obstacles would be removed. Maternal control without power assertion also helped children learn to shift attention to less frustrating aspects of the environment, because this strategy had been modelled in dyadic interaction. Rejecting mothers failed to model distraction used to reduce frustration, and additionally modelled anger as a primary response to challenging situations and a means of influencing others.

In laboratory testing repeated annually between the ages of 18 months and $4 \frac{1}{2}$ years, Kochanska et al (2002) led children to believe that they had damaged a valuable toy. The child's emotional reaction was coded for signs of guilt. Negative mothering, in particular maternal power assertion, appeared to undermine the development of children's guilt. Importantly, power assertion at 22 months predicted less guilt at 33 months, implying that the mother's use of positive influence and lesser use of threat, pressure, negative comments or anger increased the likelihood of the child manifesting guilt, which is likely to be another self-limiting influence on aggression.

\section{MENTALISATION}

\section{The development of mentalisation}

It has been suggested that our progress from non-human primate to Homo sapiens rests in our capacity to understand others' subjective experience (Tomasello, 1999), what my colleagues and I have called 'mentalisation' (Fonagy et al, 2002). Assuming that others have minds enables us to work together. However, there is a price to pay for increased harmony. The natural urge to control the behaviour of less powerful members of our group through the threat of violence becomes maladaptive (De Waal, 2000). The threat of physical violence directly interferes with mentalisation and thus it is essential to curb it. It remains adaptive in harsh social environments, such as Romanian orphanages (Smyke et al, 2002), but within the 'normative primordial troop' it was free exploration of the other's mind that ensured survival.

The conflicting requirements of retaining the potential for violence in environments beyond interpersonal understanding, and of inhibiting it in the context of the social group, led to the evolution of the device of making violence largely incompatible with a simultaneous 
representation of the subjective state of the other. The latter capacity (for mentalisation) became linked to attachment, so that we learn about minds - ours and those of others - through experiencing our internal states being understood by another mind (Fonagy et al, 2002). This is why physical aggression gradually disappears from children's behavioural repertoire over the early years of life. Physical aggression, the wish to control the other by damaging or disabling them, becomes taboo, along with incest. Attachment marks both kinds of associations.

\section{Where mentalisation fails, violence results}

In some individuals this evolutionary design proves ineffective. Thus, individuals poor at recognising mental states in others through facial expressions or vocal tones may not fully acquire mentalisation and thus inhibit their natural violence (Blair, 2001); we dismiss such individuals as 'psychopaths', to create the maximum distance between 'them' and 'us'. Other individuals may be unable to interpret minds because they have never had the opportunity to learn from mental states in the context of appropriate attachment relationships, or because their attachment experiences were disrupted. For yet others, a nascent capacity for mentalisation has been destroyed by an attachment figure who created sufficient anxiety about his or her thoughts and feelings towards the child, for the child to wish to avoid thinking about the subjective experience of others. Consequently, the child manifests an apparent callousness which is actually rooted in anxiety. The association between childhood maltreatment and externalising problems is mediated by inadequate interpersonal understanding (social competences) and limited behavioural flexibility in response to environmental demands (ego resiliency) (Shonk \& Cicchetti, 2001).

Individuals whose aggression is high in early childhood, and continues into adolescence and early adulthood, have had attachment experiences that failed to establish a sense of the other as a psychological entity. We know from other longitudinal work (Rutter et al, 2001) that environmental influences that divert the child from paths of violence and behavioural disturbance often imply the establishment of strong attachment relationships

PETER FONAGY, PhD, FBA, Sub-Department of Clinical Health Psychology, University College London, Gower Street, London WCIE 6BT, UK. E-mail: p.fonagy@ucl.ac.uk

(First received 24 September 2002, final revision 5 December 2002, accepted II December 2002)

with relatively healthy individuals. Here the adolescent can acquire implicit knowledge of minds. To reduce the risk of violence, we need to ensure that social institutions supporting development (families, nurseries, schools) are designed to enrich representations of mental states in self and others. For example, teachers should help their students to reflect on incidents of bullying, rather than adopting power-assertive strategies of exclusion.

\section{Biological evidence to link violence with impaired mentalisation}

Much biological evidence is consistent with this presupposition. The prefrontal cortex implicated in various forms of antisocial personality problems (Raine et al, 2000) is also implicated in understanding mental states. Such evidence does not preclude the relevance of social environment. Most of it pertains to the localisation of the dysfunction which violent individuals and those with specific executive problems share. It has been proposed that the primary developmental role of early attachment is neurocognitive in character (Fonagy et al, 2002). Differences in language capability between violent and non-violent individuals reflect differences in the quality of early relationship experiences rather than merely constitutional determinants restricted to language capacity. Early relationships are there not simply to protect the vulnerable human infant but to organise the functioning of the brain (Hofer, 2003) and to create the environment in which a capacity for self-mastery can be achieved by creating a representational structure for mental states.

There are many ways in which this process can be undermined - early or late, in boys and in girls, in family or school contexts, by violent or non-violent means - but the common path to violence is the momentary inhibition of the capacity for communication or for interpretation. It probably cannot arise if early experience has built an interpersonal interpretive capacity of sufficient robustness to withstand later maltreatment. Threats to self-esteem trigger violence in individuals whose self-appraisal is on shaky ground because they exaggerate their self-worth (narcissism) and are unable to see behind the threats to what is in the mind of the person threatening them.

\section{CONCLUSIONS}

Both glamorising and demonising violence help us avoid having to understand the violent mind. We should enter the violent person's subjective world, not just in order to be able to offer treatment, but also to anticipate the nature of the risks they embody both to themselves and to society. To explain is not to exculpate, but understanding is the first step in the prevention of violence. The answer to the riddle of how individuals can lose restraint over their propensity to injure others must lie in what is ordinary rather than extraordinary: normal human development.

\section{DECLARATION OF INTEREST}

None.

\section{REFERENCES}

Blair, R. J. (200I) Neurocognitive models of aggression, the antisocial personality disorders, and psychopathy. Journal of Neurology, Neurosurgery and Psychiatry, $\mathbf{7 1}$, 727-731.

De Waal, F. B. M. (2000) Primates - a natural history of conflict resolution. Science, 289, 586-590.

Fonagy, P., Gergely, G., Jurist, E., et al (2002) Affect Regulation, Mentalization and the Development of the Self. New York: Other Press.

Gilliom, M., Shaw, D. S., Beck, J. E., et al (2002) Anger regulation in disadvantaged preschool boys: strategies, antecedents, and the development of self-control. Developmental Psychology, 38 222-235.

Hofer, M. A. (2003) The emerging neurobiology of attachment and separation: how parents shape their infant's brain and behavior. In September II 'When the Bough Broke', Attachment Theory, Psychobiology, and Social Policy: An Integrated Approach to Trauma (eds S.W. Coates \& J. L. Rosenthal) New York: Analytic Press, in press.

Kochanska, G., Gross, J. N., Lin, M. H., et al (2002) Guilt in young children: development, determinants, and 
relations with a broader system of standards. Child Development, 73, 461-482.

Moffitt, T. E., Caspi, A., Harrington, H., et al (2002) Males on the life-course-persistent and adolescence-limited antisocial pathways: follow-up at age 26 years. Development and Psychopathology, 14, 179-207.

Nagin, D. S. \& Tremblay, R. E. (200I) Parental and early childhood predictors of persistent physical aggression in boys from kindergarten to high school. Archives of General Psychiatry, 58, 389-394.
Raine, A., Lencz, T., Bihrle, S., et al (2000) Reduced prefrontal gray matter volume and reduced autonomic activity in antisocial personality disorder. Archives of General Psychiatry, 57, 119-127.

Rutter, M., Pickles, A., Murray, R., et al (200I) Testing hypotheses on specific environmental causal effects on behavior. Psychological Bulletin, 127, 291-324.

Shaw, D. S., Gilliom, M., Ingoldsby, E. M., et al (2003) Trajectories leading to school-age conduct problems. Developmental Psychology, 39, 189-200.
Shonk, S. M. \& Cicchetti, D. (200I) Maltreatment, competency deficits, and risk for academic and behavioral maladjustment. Developmental Psychology, 37, 3-17.

Smyke, A. T., Dumitrescu, A. \& Zeanah, C. H. (2002) Attachment disturbances in young children. The continuum of caretaking casualty. Journal of the American Academy of Child and Adolescent Psychiatry, 4I, 972-982.

Tomasello, M. (1999) The Cultural Origins of Human Cognition. Cambridge, MA: Harvard University Press. 